\title{
La segmentación socioeconómica del espacio: la comunidad ecológica y la toma de Peñalolén
}

\begin{abstract}
During 2003, an urban conflict was generated between the members of an ecological community and the inhabitants of a land seizure settlement in the municipality of Peñalolen. This conflict resuscitated the debate over urban segregation and the desire for integration of diverse social and cultural groups in the city. We present the results of a qualitative and descriptive study which had the objectives of recognizing the contradictory aspects of socioeconomic segmentation represented in the opinions of chileans in relation to the conflict, also to analyze the basic arguments of the inhabitants of the ecological community in rejecting the use of sites bordering on the community by these new settlers. The results confirm assumptions about the use of urban land as a mechanism for utility maximization and a strategy of differentiation. Also important is the motivation and search for identity in the choice of place in which to settle.
\end{abstract}

Key words: urban segregation, differentiation, gated communities, fragmentation, citizenship

\section{Resumen}

Durante el año 2003 en la comuna de Peñalolén se produjo un conflicto urbano entre los integrantes de una comunidad ecológica y los habitantes de una toma ${ }^{1}$ de terreno. Esta situación reactivó la discusión acerca de la segregación urbana y la voluntad de integración en la ciudad de sectores social y culturalmente diversos. Presentamos los resultados de un estudio cualitativo descriptivo, que tuvo como objetivos reconocer los aspectos contradictorios de la segmentación socioeconómica del espacio presentes en las opiniones de ciudadanos chilenos en torno al conflicto, y analizar los fundamentos sostenidos por los habitantes de la comunidad ecológica para rechazar la instalación de los pobladores en los terrenos aledaños a dicha comunidad. Los resultados confirman los supuestos sobre la ocupación del territorio urbano como mecanismo de maximización de utilidades y estrategia de distinción. También, la importancia de la motivación y la búsqueda de identidad en la elección del lugar donde habitar.

Palabras claves: segregación urbana, distinción, condominio cerrado, fragmentación, ciudadanía. 


\section{Introducción}

$\mathrm{E}$ l condominio privado ha sido asociado a la privatización y destrucción del espacio público que han ido experimentando las ciudades en los últimos decenios, poniendo en jaque para algunos urbanistas las condiciones de posibilidad de la convivencia e integración social en la ciudad (Giglia, 2003). Si bien Santiago no compartiría, en rigor, los rasgos de aquello que Manuel Castells (2004) llama las mega ciudades - por sus dimensiones y menor importancia sociopolítica y estratégica - sí ha sufrido el impacto de las fuerzas de mercado que estructuran la distribución espacial de los grupos sociales en la ciudad, generando constelaciones discontinuas de fragmentos espaciales, piezas funcionales $y$ segmentos sociales (Borja, 2003). De ahí que Françoise Choay proponga sustituir el término de ciudad por "urbano", para referirse a "espacios fragmentados y recíprocamente segregados" (Giglia, 2003, p. 3). De este modo, el "mosaico social" de la ciudad "comienza a transformarse y a mostrar formas de agrupamiento que rompen de alguna forma la tendencia a acumular en determinadas áreas a estratos socioeconómicos similares" (Hidalgo, 2003, p. 5). Se reconoce como principal señal de este fenómeno a los condominios cerrados y se plantea que estas modalidades juegan un papel decisivo en la reestructuración de las ciudades latinoamericanas (Sabatini, 2001).

Esta creciente privatización del espacio público puede ser analizada como una pérdida progresiva del derecho de todos a los bienes públicos. Si asumimos la ciudad como un bien público, en ella debieran cristalizarse los ideales de justicia e igualdad asociados a las democracias pluralistas modernas y traducidos en la existencia de ciudades de y para todos los ciudadanos. Este presupuesto ético/políti-

Académica Departamento de Trabajo Social, Universidad Católica Cardenal Raúl Silva Henríquez, Santiago, Chile. E-mail: amalvare@ucsh.cl.

Una toma constituye la ocupación ilegal de un terreno fiscal o privado por parte de personas solas y/o en grupos de familias que se instalan en él de manera provisoria o permanente y que no cuentan con la autorización formal ni legal de su propietario.

Recibido el 7 de marzo de 2006

Aceptado el 17 de julio de 2006 co nos instaría a reconocer en los condominios de la ciudad de Santiago expresiones de autosegregación sustentadas en la posibilidad que ellos brindan a sus habitantes de usar y gozar con exclusividad los espacios que constituyen el territorio comunitario y hacer efectivo un proyecto de vida que representa los intereses y las aspiraciones de quienes optaron por ser parte de él. En este artículo se postula que la cuestión de la autosegregación por la vía del condominio cerrado no constituiría una mera práctica individual o sectorial al servicio de la simple manifestación de gustos y/o preferencias de un grupo. Más bien, coincidiendo con Giglia, se vería como una estrategia orientada a la creación de espacios para la constitución de identidad y la búsqueda, explícita o latente, de diferenciación social mediante el uso del espacio urbano (Giglia, 2003).

Aunque la autosegregación no sería una estrategia solamente atribuida a los sectores medios o medio altos, el estudio se centró en el análisis de un caso representativo de aquello que la autora referida denomina espacios residenciales cerrados. Ellos se definen por las posibilidades de cierre y separación con el exterior, "generando una privatización o una reducción del espacio público" (Giglia, 2003, p. 7). El espacio público había sido hasta hoy día, según Simmel, el lugar del libre acceso y el libre tránsito. En los espacios residenciales cerrados, ello se pasa por alto, lo que permite demostrar el grado en el cual estos espacios y "sus barreras se han vuelto "naturales" en el paisaje y en la experiencia urbana” (Giglia, 2003, p.7).

Si bien la Concertación de Partidos por la Democracia, coalición gobernante en Chile desde el año 1990 hasta la fecha, adhiere a la fórmula del crecimiento con equidad, la concentración de la riqueza que exhibe el país, no solo por la vía del ingreso sino también por la desigualdad socioeconómica reflejada en la distribución de la pobreza por regiones y comunas, ha crecido. El Estado buscaría contrarrestar esta situación por el aumento del empleo que generaría el crecimiento económico y por el desarrollo de políticas sociales focalizadas hacia la pobreza y la exclusión social. La propuesta de política social de vivienda de la actual presidenta Michelle Bachelet podría representar un ligero giro de la política pública en este ámbito, al impulsar una serie de medidas que, junto con 
asignar viviendas, permitirían mejorar la calidad de las mismas y su integración a la ciudad. En esta dirección, se ha aumentado el monto de subsidio para lograr mayor superficie mínima $\left(40 \mathrm{~m}^{2}\right)$, creándose, además, un subsidio a la localización dirigido a la compra de terrenos al interior de la ciudad. Por último, se estaría tramitando una ley en el parlamento que permitiría una mayor regulación del uso del suelo, entre otras medidas ${ }^{2}$. Este giro en la política social de vivienda, pone de manifiesto que la segregación urbana ha comenzado a llamar la atención de los gobiernos, en tanto se prevé que este tipo de ocupación del territorio tendrá consecuencias sobre la conformación de la ciudad presente y futura, no solo en términos urbanísticos, sino también, y fundamentalmente, en relación con la construcción de ciudad como espacio democrático.

Este artículo se inscribe en una perspectiva urbanística que entiende la necesidad de contacto social entre grupos social y culturalmente heterogéneos, como factor necesario y deseable para la construcción de una democracia pluralista. Esto supone un mínimo de tolerancia y aceptación de la cohabitación entre sectores, teniendo como referente ético/político la integración social, la posibilidad de ejercicio de derechos ciudadanos de primera, segunda y tercera generación, equidad en el uso del suelo urbano, goce de la infraestructura, hábitat y paisaje urbano, derecho a la belleza y acceso a áreas verdes. En resumen, la posibilidad no solo de disfrutar de una buena calidad de vida, sino también de vivir una vida de calidad.

\section{La ciudad de Santiago}

Existe consenso en la teoría social urbana en estimar la influencia de los modelos de desarrollo económico y social vigentes en cada período histórico sobre las formas de organización socio espacial, política y territorial de las ciudades y el tipo de actividades y funciones a las cuales sirve prioritariamente su diseño e infraestructura. J. Borja, en su libro La Ciudad Conquistada (2003), estima que el movimiento moderno asumido en

\footnotetext{
Ministra de Vivienda, Presentación Nueva Política Habitacional, Ministerio de Vivienda y Urbanismo (Junio 2006).
}

una óptica más compleja de transformaciones sociales y ampliación de oportunidades, no acusa la misma simplicidad que el urbanismo funcionalista de los proyectos desarrollistas. La vinculación de dicho movimiento con la idea de un Estado representante y garante del bien común redundó en una preocupación por la vivienda masiva, la higiene y el paisaje urbano, que, junto a la importancia atribuida a las comunicaciones, fueron el reflejo de una visión productivista no especulativa de la ciudad y una preocupación por las condiciones y calidad de vida de la población trabajadora.

Coincidentes con esta perspectiva, Raposo, Raposo y Valencia (2005) destacan que las iniciativas emprendidas en Chile por el llamado Estado de Compromiso buscaron producir un espacio habitacional que organizara una modelación de la vida cotidiana que se desarrolla en el marco de un estatuto implícito de dignidad habitacional compatible con los requerimientos generados por la estructura social del industrialismo fordista, para sostener la reproducción de la fuerza de trabajo. La crisis del modelo industrial desarrollista nacional se expresó en la creciente expansión de los asentamientos irregulares urbanos y su correlato de contenciones establecidas como intervenciones programáticas del Estado (p. 3).

No obstante, la combinación entre las prioridades del modelo industrial capitalista en términos de actores estratégicos y la hegemonía de un pensamiento racionalista, determinó de manera significativa la intervención en la ciudad y la forma de dar respuesta a las necesidades sociales de los ciudadanos, en particular de quienes no tenían posibilidades de adquirir una vivienda a partir de sus propios ingresos y recursos. Los efectos perversos del urbanismo funcionalista se dejaron sentir en las ciudades latinoamericanas - y por tanto, en Santiago de Chile - en la sectorización de las políticas de intervención en el espacio urbano y, a partir de ello, en la generación de dinámicas urbanas que contribuyeron a reforzar mecanismos de discriminación y segregación social.

Para V. Espinoza (1988), Santiago se habría constituido desde su fundación sobre un plano socialmente segregado, que a 1900 había cristalizado en sectores claramente delimitados y dife- 
renciables: el centro, consolidado y hermoseado, principalmente en su carácter comercial y administrativo; luego, las áreas residenciales de grupos de medianos y altos ingresos (p. 16). Mientras, "los pobres se ubicaban fuera de este cordón, en suburbios con evidentes problemas de infraestructura sanitaria, equipamiento y construcciones con un alto nivel de deterioro o en abierto mal estado" (Espinoza, 1988, p.16).

S. Hevia (2003), señala que, en la medida en que la clase dirigente y los gobiernos de turno asumían en forma progresiva la inminencia del problema habitacional y temían por su posible impacto en la estabilidad social, sobre todo cuando los sectores pobres también se movilizaban, se van institucionalizando una serie de iniciativas (p. 5). Entre las más significativas se encuentran la Caja de la Habitación Popular en 1936, con el objeto de que las instituciones de previsión, industriales y agrícolas, colaboren en el otorgamiento de préstamos para vivienda a sus afiliados, fomentando así la construcción (Hevia, 2003).

Pero no era solo el Estado el que actuaba a través de la creación de organismos que intentaban suplir el déficit habitacional; también se destacan la presión y la movilización popular por el derecho a la vivienda. A partir de la década de los 40, puntualiza Hevia (2003), las grandes ciudades, en especial Santiago, como centro de localización industrial, comienzan a actuar como foco de atracción para la población campesina migrante. Este proceso migratorio cambió una pauta de crecimiento caracterizado por la densificación a través del conventillo por el crecimiento en extensión con el uso de las comunas adyacentes al centro. Entre el ' 40 y el ' 52 el área residencial de Santiago creció en $40 \%$, básicamente a través del sistema de loteos, consistente en la subdivisión para uso urbano de terrenos agrícolas periféricos. En forma simultánea a este proceso, se puede apreciar el desarrollo de ocupaciones ilegales bajo la forma de "callampas"3. La demanda abultada de habitación producto del proceso migratorio llevó a los sectores populares a la ocupación de terrenos en forma de

3 Se las llamó así, por ubicarse en terrenos húmedos por la forma de instalación y de crecimiento por agregación callampas, que fue desplazando progresivamente al conventillo (p. 5).

Fue entonces la callampa, y en consecuencia, el modelo de asentamiento urbano de las poblaciones callampa lo que se constituyó progresivamente en la modalidad a través de la cual los pobres solucionaban su problema de vivienda. Esto se dio teniendo como telón de fondo una institucionalidad débil y restringida en comparación con la magnitud de la demanda. Las callampas resultaron ser entonces asentamientos densamente poblados, con condiciones sanitarias deficientes, a lo que debían agregarse inundaciones, epidemias e incendios. Entonces, una vez ocupado el terreno, se iniciaba para los pobladores la lucha por lograr en ese territorio una solución definitiva. Esta situación, nos dice Hevia (2003), se iría transformando en un conflicto latente de mucha explosividad que, pese a las promesas y a las iniciativas parciales, terminaría expresándose fuera de los mecanismos establecidos de solución habitacional.

Cabe aquí destacar las iniciativas emprendidas durante el gobierno de Salvador Allende en materia de vivienda social y de lucha contra la segregación urbana como asunto público. Como se indica en el trabajo de Raposo et al. (2005) a comienzos de la década de los 70, los objetivos de transformación social que animan la labor del gobierno de la Unidad Popular en nuestro país se traducen, en el plano de las políticas de desarrollo urbano, en acciones programáticas destinadas a iniciar un proceso de reducción de las distancias sociales que marcan la acentuada segregación social en el área metropolitana (p. 1).

Si bien existe consenso en sostener que Santiago se desarrolló sobre la base de un patrón más o menos acentuado y persistente de segregación global (ricos a un lado, pobres al otro), con la consecuente polarización espacial resultante, los mecanismos concretos de transmisión de la desigualdad social vinculada a la desigualdad socioespacial habrían cambiado. Lo anterior, entre otros fenómenos, como efecto de los procesos de transformación económica operados en Chile a partir del Golpe Militar de 1973.

Antes de las reformas neoliberales emprendidas por el Gobierno Militar, primó en nuestro país una 
lógica no mercantil en lo referido a la asignación de espacio urbano a ciertos grupos socioeconómicos por la vía de la zonificación y las tomas de terreno ${ }^{4}$. Segun Hidalgo (2003), la ausencia de regulación, la alta rentabilidad de los proyectos inmobiliarios, más el sistema de concesiones viales, entre otros factores, movilizaron a los privados en la búsqueda de rentabilidades atractivas para sus inversiones (...), potenciando la expansión física de las áreas metropolitanas hacia los bordes y, también, hacia sectores rurales aledaños, tradicionalmente empleados como suelo agrícola (p. 2). Esto generó la exacerbación de un proceso de suburbanización que ha traído como consecuencia una "expansión tentacular de la mancha urbana central que ha desbordado continuamente los límites de la ciudad, extendiéndose hacia las áreas rurales circundantes" (Hidalgo, 2003, p. 2).

Coincidente con esta apreciación, López (2004) señala que durante los años noventa, los procesos territoriales protagonistas en la cultura urbanística internacional se han visto marcados por la combinación entre una acelerada y difusa ocupación del suelo periférico con una singular renovación de los espacios centrales. A ello se han sumado dos rasgos nuevos. Por una parte, el mayor protagonismo de los procesos capitalistas, que han agudizado y acelerado las tendencias privatizadoras en el espacio, los bienes y los servicios y, por otra, la proliferación de modelos suburbanos de contrastadas densidades, tanto para la residencia como para la industria y los espacios comerciales y de ocio (p. 1).

Si bien se constata la existencia de abundantes estudios referidos a los orígenes de la segregación, su evolución, manifestaciones puntuales y consecuencias, no se observa la misma proporción de investigaciones y reflexiones que den cuenta de la visión de quienes escogen esta forma de habitar la ciudad y de la percepción que ello genera en el resto de los ciudadanos. Poco se conoce acerca de sus motivaciones, más allá del deseo de querer vivir entre gente como uno y del temor a la delincuen-

$4 \quad$ Esta última ha sido identificada por autores como G. Salazar, M. Garcés y V. Espinoza, entre otros, como la estrategia empleada por los sectores populares en Chile a partir de la década del 50' hasta el 1973, para reivindicar su derecho a la vivienda y a la ciudad. cia. Asimismo, tampoco se sabe mayormente del impacto subjetivo que la autosegregación genera entre quienes viven en barrios más integrados a la trama urbana.

En consecuencia, el conjunto de procesos descritos anteriormente, más los cambios políticos y el impacto de las transformaciones económicas sobre las aspiraciones, intereses y expectativas de las diferentes clases sociales han tenido una importancia capital en el desarrollo socioespacial de la ciudad de Santiago.

\section{El conflicto}

La historia de la comunidad ecológica se remonta a la década del ochenta, momento en que los propietarios de los terrenos resultantes de la parcelación del fundo Lo Hermida, ocurrida en los años 70', comienzan a vender estas tierras a individuos y familias que deseaban llevar un estilo de vida en conformidad a ciertos principios ecológicos y medio ambientales y a la necesidad de distanciarse de la dinámica urbana santiaguina, con sus cada vez más crecientes problemas de contaminación ambiental, acústica y de inseguridad ciudadana. En las 150 hectáreas de la comunidad ecológica viven 330 familias. Es decir, en cada hectárea viven 2 familias. A razón de 4 personas por familia, en cada hectárea viven 8 personas. Cada persona de la comunidad ecológica dispone de mil 136 metros cuadrados para vivir (Miranda, 2003). Los habitantes de la comunidad ecológica se hicieron conocidos por la opinión pública chilena en tanto miembros de dicha comunidad ${ }^{5}$ a raíz de un conflicto sostenido con los pobladores de una toma de terreno de la misma comuna. Este conflicto se desencadena a partir del anuncio del gobierno chileno, representado en la figura del entonces ministro de la vivienda, de instalar en dos predios aledaños a la comunidad ecológica, 900 viviendas sociales para albergar a alrededor de 980 familias pertenecientes a la toma. Esta medida, señala Bañados (2003), ocasiona el rechazo generalizado de los habitantes de la comunidad ecológica, quienes, entre otras razones, aducen

Hacemos esta distinción pues entre ellos se encuentran actores, políticos y personajes del mundo público conocidos por sus apariciones en los mass media, ejerciendo otros roles que aquellos que asumieron en el conflicto. 
que se quintuplicaría la densidad de población del sector como efecto de la instalación de 5 mil personas más en apenas 10 hectáreas.

Respecto de este punto, Hidalgo (2003) indica que han existido conflictos relacionados con la dimensión social de los condominios; también se han producido efectos en el espacio urbano y rural en el cual se han insertado los proyectos, que han tenido que ver con algunas modificaciones en la morfología de las ciudades asociadas a significativos cambios en la densidad habitacional, en lugares de bajo porcentaje de constructibilidad, con lo cual han aumentado considerablemente los flujos vehiculares y los requerimientos en equipamientos y servicios (p. 6). Estos efectos perversos podrían avalar, en parte, las aprehensiones de los habitantes de la comunidad ecológica para aceptar la instalación de los pobladores como vecinos.

El conflicto, en cuya gestión el Estado jugó un papel fundamental, significó la confrontación de los intereses de dos sectores de ciudadanos. Los pobladores de la toma alegaban su derecho a una vivienda propia construida en los terrenos de la comuna, puesto que se sienten parte de ella y han desarrollado identidad en torno a la misma, anticipándose así a lo que ha sido una constante de la política de vivienda en Chile, a saber, la construcción de soluciones habitacionales en suelos de bajo valor comercial, generalmente ubicados en la periferia de la ciudad. En este caso, la propuesta gubernamental fue diferente: adquirir terrenos en la comuna, favoreciendo así la permanencia de los pobladores en ella. En tanto, los habitantes de la comunidad ecológica sostenían que el traslado de las familias de la toma significaría el crecimiento abrupto de la población del sector, pasando de 25 a 400 personas por hectárea (un aumento de 18 veces la densidad actual), lo que ocasionaría "no solo un impacto ambiental, sino también urbano, social y de seguridad ciudadana” (Bañados, 2003, p. 4).

En torno a la defensa de los intereses de cada una de las partes comprometidas, se articularon discursos y prácticas cuya aspiración parecía ser la misma: el derecho a la vivienda y a una buena calidad de vida. Sin embargo, la situación generó profundas controversias en distintos sectores ciu- dadanos, principalmente hacia la posición de los habitantes de la comunidad ecológica y hacia la actitud del gobierno.

Los habitantes de la comunidad ecológica fueron acusados de actitudes discriminatorias hacia los pobladores y de reforzar la segregación urbana. Asimismo, se los acusó de anteponer su opción ecológica y medioambiental al derecho de los pobladores de la toma a habitar una vivienda digna y a permanecer en su comuna de residencia, junto con emplear este mismo discurso con el propósito encubierto de esconder su temor a que los terrenos donde están emplazadas sus viviendas y también estas perdieran plusvalía.

El gobierno - si bien definió su papel empeñándose en encontrar una solución definitiva al problema y rechazando el comportamiento de los habitantes de la comunidad ecológica - desde el punto de vista de algunos colectivos urbanos, medio ambientales y activistas críticos a su gestión en materia de urbanismo, solo buscó invisibilizar la falta de políticas sustentables de largo plazo para Santiago. También dejaría en evidencia el carácter arbitrario con que la autoridad ha actuado en esta materia en los últimos años. Prueba de ello sería la propuesta de modificar, puntualiza Miranda (2003), el Plan Regulador Metropolitano, de modo de ocupar 90 mil hectáreas actualmente destinadas a tierras agrícolas, con el objetivo de construir viviendas para familias de altos ingresos. Ello implicaría la expansión horizontal de Santiago, situación que tendría consecuencias nefastas para la calidad de vida del conjunto de los habitantes de esta región (p. 1).

Las alrededor de 980 familias que, en principio, pensaban ser trasladadas a los terrenos colindantes a la comunidad ecológica, si bien se mostraron fuertemente cohesionados en torno a la figura de sus dirigentes y organizaciones - reivindicando su derecho a ocupar los terrenos que les serían asignados por el gobierno - luego de casi un año de conflicto, terminaron firmando un convenio que implica que ya no ocuparán dichos terrenos. No obstante, no todas las familias de la toma reaccionaron favorablemente frente al ofrecimiento del gobierno: 13 de ellas, que representan un $7 \%$ del total, no apoyaron las conversaciones, 
quedando fuera del protocolo de entendimiento, por ser consideradas "rebeldes". Sin embargo, ello no las inhabilita para que puedan postular de la misma forma que otras familias a los fondos concursables de los más de 22 mil subsidios que entregará el ministerio ${ }^{6}$.

Es posible plantear, por las características que adquiere la controversia entre pobladores, comuneros y gobierno, que estamos frente a un desacuerdo cuya génesis se remonta al problema de la segregación urbana. En razón de lo anterior, estimamos que la situación descrita ofreció valiosas oportunidades de análisis de los argumentos esgrimidos para la justificación de las distintas posiciones adoptadas. Cabe destacar que nuestro propósito no fue realizar un contrapunto entre las opiniones de pobladores y comuneros, sino más bien aprovechar las reacciones de la ciudadanía frente al conflicto, incluyendo, naturalmente, las declaraciones de los habitantes de la comunidad ecológica, profundizando en aquello que estaría implícito en la defensa de un estilo de vida y en el componente de segregación y autosegregación allí presente.

\section{Enfoque metodológico, supuestos y objetivos}

El estudio fue de tipo cualitativo descriptivo y tuvo como unidad de análisis las declaraciones formuladas por ciudadanos chilenos entre los meses de julio y noviembre de 2003 (pleno desarrollo del conflicto) en foros ciudadanos creados en medios de prensa electrónicos nacionales. Se trató, puntualmente, de foros organizados por los diarios La Segunda y El Mercurio ${ }^{7}$. También se consideraron las declaraciones hechas por integrantes de la comunidad ecológica en este mismo periodo teniendo como fuentes de información los diarios

\footnotetext{
6 Habitantes de la toma de Peñalolén firmaron acuerdo definitivo con las autoridades, jueves 3 de marzo de 2004 (www.radiocooperativa.cl).

Se trata de dos medios de prensa nacional dirigidos fundamentalmente a lo que se conoce como población A, B, C 1, C2 en el sistema de estratificación social para estudios de mercado. Ello corresponde a población de clase media acomodada y alta que reciben ingresos que van desde los 3.000 (C1 y C2) a los 7.000 dólares y más (A y B) y habitan las comunas del sector oriente de la capital, donde se concentran los más altos ingresos.
}

La Nación, Las Ultimas Noticias y La Cuarta. En ambos casos la muestra fue de carácter dirigido y su tamaño se determinó a partir del criterio de saturación, que significa estimar su envergadura por la diversidad de discursos encontrados relativos a los temas sobre los que se está indagando. La muestra se cierra cuando no es posible reconocer nuevos discursos. Para el caso de los ciudadanos que opinaron en los foros, se seleccionaron 80 declaraciones de un total de 300 que fueron examinadas. Cómo técnica de ordenamiento y análisis de la información, se empleó, en ambos casos, el análisis categorial sin categorías predefinidas. La formulación de las categorías se hizo teniendo como punto de apoyo los supuestos y preguntas de investigación y el marco de referencia.

Para definir las categorías, se procedió a la lectura reiterada del material. Las declaraciones corresponden tanto a hombres como a mujeres de distintas edades y ocupaciones. Se escogieron foros ciudadanos porque las preguntas que en ellos se formulaban permitían responder a los objetivos del estudio. Estas preguntas apuntaban a conocer la legitimidad conferida por la ciudadanía a la actitud de rechazo de los miembros de la comunidad ecológica hacia la instalación de los pobladores en terrenos aledaños a ella.

El estudio se planteó como supuestos que la reacción de los habitantes de la comunidad ecológica evidenciaba que los espacios residenciales cerrados serían el resultado de procesos socio-espaciales específicos asociados a cuestiones de identidad y distinción. Asimismo, que la actitud de la ciudadanía frente al conflicto estaría mediada por la legitimidad conferida hoy día a la maximización de utilidades y a la acumulación por la vía de la ocupación del territorio urbano.

\section{Categorías que emergen del tratamiento de la información}

A partir de la lectura reiterada de la información, fue posible formular las siguientes categorías: identidad / motivación, integración / exclusión, diferenciación/ distinción, seguridad y rol del Estado. En la categoría identidad/motivación se agruparon las opiniones que aludían directa o indirectamente a lo que se conoce como identidad social. Es decir, aquel conjunto de referentes 
simbólicos que un individuo, grupo o clase social, reconoce como propios y que le ayudan a situarse respecto de los otros. Así, el espacio social se fragmenta entre quienes el sujeto percibe como iguales (homogeneidad sociocultural) y aquellos que considera diferentes. Es decir, aquellos a los que no se quiere parecer y con quienes le resultaría difícil identificarse. Por su parte, las motivaciones dicen relación con lo que impulsa al individuo a actuar de determinada manera. Se consideró identidad y motivación dos dimensiones estrechamente vinculadas entre sí, en tanto las decisiones y acciones que emprenda un individuo o grupo evidencian el carácter de sus motivaciones y constituyen, al mismo tiempo, manifestaciones de su identidad.

En cuanto a la integración/exclusión, se entendió la primera como el proceso a través del cual individuos y grupos se incorporan activa y efectivamente a los sistemas y subsistemas que constituyen el orden social. La exclusión social, en tanto, remitiría al proceso contrario, es decir, al quiebre o debilitamiento de los lazos que unen al individuo con la sociedad (Barros, de los Rios y Torche, 1996). En esta categoría se reunieron todas aquellas opiniones que subrayaban la diferencia entre nosotros y los otros, apareciendo la imagen de los otros reificada en torno a un conjunto de características negativas (delincuencia, robo, suciedad). Para la definición de las nociones de diferenciación/ distinción, se tomó como referencia al sociólogo francés Pierre Bourdieu (1977), que las entiende como mecanismos a través de los cuales las clases sociales buscan, mediante discursos, prácticas, usos y costumbres asociados a los componentes constitutivos del capital cultural de la burguesía, distanciarse de las prácticas, usos y costumbres de clases sociales percibidas como inferiores.

En la categoría seguridad se agruparon todas las declaraciones que enfatizaban temas relativos a seguridad ciudadana, la que se relacionaría con dos aspectos: el índice objetivo de victimización que existe en una sociedad determinada, es decir, el grado en el cual una persona ha sido o puede ser víctima de un asalto, homicidio, agresión u otra forma de vulneración de su integridad física y psicológica, información que entregan las estadísticas de victimización real. Y también se vincula con lo que se conoce como sensación de inseguridad o inseguridad subjetiva, es decir, la percepción que tiene el habitante urbano respecto de lo seguro o inseguro que resulta su entorno, sea este un barrio o la ciudad en su conjunto, independiente si esta persona ha sido o no victimizada.

En tanto la categoría rol del Estado agrupó declaraciones que consideraban la génesis del conflicto en un manejo e intervención inadecuados del gobierno en la figura de su representante, el ministro de la vivienda. Se incluyeron también alusiones relativas al papel que le corresponde jugar al Estado en relación con los problemas de vivienda de los ciudadanos, en particular de los más pobres, y con la actitud que debiera asumir en la defensa de estilos de vida forjados con esfuerzo dentro de un marco legal que regula los comportamientos y los límites de la intervención gubernamental.

Finalmente, en la categoría valor del esfuerzo y la propiedad se reunieron todas aquellas declaraciones que destacaban el valor del esfuerzo individual/familiar expresado en el ahorro, el sacrificio, la capacidad de diferir la satisfacción presente en pro del bienestar futuro. Es el empeño invertido en el logro de determinadas aspiraciones materiales, entre las cuales la vivienda ocuparía un lugar central. Como legitimidad y defensa de la propiedad privada se entendieron aquellos dichos que exaltaban su valor por sobre otros aspectos o dimensiones del funcionamiento social, como, por ejemplo, la solidaridad, la justicia o la igualdad, y la legitimidad que estaría asociada a su defensa.

\section{Análisis de la información}

Una de las primeras cuestiones que llaman la atención es que las categorías no encuentran un respaldo homogéneo en términos de la cantidad y densidad de opiniones que las fundamentan. La distinción/diferenciación, el valor del esfuerzo y la legitimidad de la propiedad privada, junto con el rol del Estado, aparecen invocados con mayor frecuencia como argumentos para legitimar el rechazo de los comuneros a la instalación de los pobladores. Mientras, la identidad/motivación, la integración/exclusión y la seguridad surgen con menos frecuencia para apoyar o rechazar la medida gubernamental. 
En el caso de las declaraciones de los miembros de la comunidad ecológica, solo es posible pesquisar como fundamentos de su oposición la identidad/motivación - la más frecuentemente invocada - junto con referencias precisas al rol del Estado. En tanto la diferenciación/distinción, aunque presente, no aparece como un argumento importante en las declaraciones de los comuneros para defender su opción.

No fue posible reconocer en los dichos de los habitantes de la comunidad ecológica ninguna opinión que sostuviera su rechazo a la instalación de los pobladores en cuestiones asociadas al valor del esfuerzo y a la defensa y legitimidad de la propiedad privada, así como tampoco identificar fundamentos relacionados con el tema de la seguridad; no obstante, esta última es una de las motivaciones más frecuentes - según la literatura consagrada al tema - al momento de escoger vivir en un condominio privado. Tal vez ello se relacione con el perfil sociocultural de sus habitantes, perfil que aparentemente se distanciaría de los discursos que reducen la cuestión de la seguridad ciudadana a la delincuencia y a la implementación y proliferación de mecanismos de control y vigilancia. Lo anterior implica ser cuidadosos al sacar conclusiones con relación a este punto.

Para los ciudadanos que opinaron en los foros, la seguridad, en cambio, sí es esgrimida como argumento para legitimar el rechazo de la comunidad a la instalación de los pobladores. No obstante, aparece fusionada en los discursos sobre la diferenciación/distinción, en que la delincuencia sería otro rasgo más del estigma que pesa sobre los pobladores y que constituiría un componente de su identidad.

El gobierno, en la persona del entonces ministro de la vivienda, Jaime Ravinet, es el principal blanco de las críticas de ciudadanos y comuneros y es a quien se le atribuye la responsabilidad en la generación y agudización del conflicto. Este sostienen dirigentes de la comunidad ecológica y ciudadanos - habría actuado en forma arbitraria al tomar unilateralmente la decisión de instalar a los pobladores en un sector de la comuna, que implicaría pasar a llevar el plano regulador de la misma, haciendo peligrar la seguridad de sus habitantes.
Ello por cuanto se trataría de terrenos que, por su cercanía a la cordillera y su particular morfología, no son aptos para albergar gran cantidad de población. Al mismo tiempo, algunas opiniones de los foros reforzarían las aprehensiones de urbanistas chilenos que ven en la actuación del gobierno una evidencia más de la falta de planificación urbana y de proyecto de ciudad para Santiago.

\section{Comentarios más relevantes por categorias}

Las dimensiones sociales y motivacionales de la identidad aparecen claramente reflejadas en las declaraciones de los comuneros. Estos serían personas unidas por cierta homogeneidad (dimensión social) que se traduce en que comparten un modo de vida (dimensión motivacional). Esto coincide con lo que Giglia (2003) plantea cuando sostiene que aun asumiendo la dimensión desestructurante del condominio privado, sería reductivo mirar los espacios cerrados solo con la lente de la desintegración urbana o de la reducción de lo público; también es posible percibir que en estos espacios se están gestando nuevas formas de vivir y pensar la ciudad (p. 27), hipótesis que tienden a reafirmar tanto los ciudadanos que opinaron en los foros como los habitantes de la comunidad ecológica.

También es posible reconocer hábitos, costumbres, prácticas y códigos de relación intracomunitarios y con el entorno social y ambiental que serían propios de este grupo. Para Giglia (2003), la búsqueda de seguridad, la idea de la homogeneidad sociocultural hacia adentro y la búsqueda de distinción respecto del afuera serían tres estrategias que actuarían juntas imprimiendo al condominio el carácter de una experiencia socioespacial específica, creando y recreando tipos de sociabilidad, perspectivas de ciudad y de experiencia urbana particulares.

Resulta interesante hacer referencia a un aspecto no considerado en este estudio en la definición de identidad social, cual es la dimensión de lugar. Esta dimensión se relaciona con la noción de Identidad Social Urbana propuesta por Pol, Guardia, Valera, Wiensenfeld y Uzzell (2000), quienes siguen el desarrollo del concepto de place-identity, que podría ser entendido como la identidad de lugar. Esta sería considerada como una dimensión de la identidad de selfy consiste en un conjunto de cogniciones referen- 
tes a lugares o espacios donde la persona desarrolla su vida cotidiana y en función de los cuales puede establecer vínculos emocionales y de pertenencia a determinados entornos. Estos vínculos son tan importantes como aquellos que establecemos con las distintas personas con quienes nos relacionamos. En la base de esta estructura se encuentra lo que estos autores llaman el pasado ambiental del individuo, así como el conjunto de significados producidos socialmente en torno a estos espacios y que hemos ido incorporando a nuestra experiencia y relaciones.

Esta idea de pasado ambiental sería uno de los núcleos centrales de la argumentación de los miembros de la comunidad ecológica para defender su derecho a preservar intacto el entorno de sus viviendas. La identidad de lugar configuraría, a juicio de los autores citados, un verdadero depósito cognitivo, del cual, afirman, el individuo no es consciente excepto cuando siente su identidad amenazada, como se demuestra en el caso analizado. Esta dimensión de la identidad, subrayan Pol et al. (2000), permite a la persona reconocer propiedades de los entornos nuevos que se relacionan con su pasado ambiental, favorecer un sentido de familiaridad y la percepción de estabilidad en el ambiente, dar indicios sobre cómo actuar, determinar el grado de apropiación o la capacidad para modificar el entorno y, por último, favorecer un sentimiento de control y seguridad ambiental (pp. 1-6).

A modo de conclusión provisoria del análisis de esta categoría y siguiendo a los autores citados, parece que mientras más fuerte sea una identidad social en una comunidad, el horizonte de la sostenibilidad es potencialmente más viable ( $\mathrm{Pol}$ et al., 2000). Ello encontraría un correlato en la experiencia de los habitantes de la comunidad ecológica, donde es posible observar esta relación entre identidad social - articulada en torno a un proyecto de vida compartido - y la lucha por preservar un estilo de vida en la ciudad.

Lograr este nivel de cohesión sobre una idea común de ciudad es más difícilmente practicable en vecindarios donde la identidad es más débil, y, por lo tanto, más débil también la respuesta ciudadana frente a la intervención del entorno. Incluso, si ello acarrea perjuicios importantes a la calidad de vida de los habitantes, como ha ocurrido con las autopistas licitadas en zonas residenciales de la ciudad de Santiago, que han fragmentado espacialmente determinados sectores, con consecuencias negativas en el plano de la seguridad vial, la contaminación ambiental y acústica y la segregación urbana. Así, el lugar actúa como elemento aglutinante de la colectividad, y como símbolo de su permanencia en el tiempo, cambiando de significado a través de los mecanismos de apropiación, con sus respectivos componentes de accióntransformación/significación-identificación que operan de manera individual y colectiva (Pol et al., 2000). Los lugares con una fuerte identidad ayudan a aglomerar a la colectividad y a mantener su identidad social. En este sentido, la vertebración y la cohesión social crean identidad de lugar y, a su vez, los lugares con identidad facilitan la integración social, concluye el trabajo citado.

Un segundo elemento que parece significativo se relaciona con la calificación de ilegitima que recibe la actitud de los habitantes de la comunidad, definiéndose ésta desde lo que se consideraría un aspecto contradictorio de la Identidad Social de quienes componen este colectivo. Si bien son mucho menos frecuentes que las anteriores, parece interesante reflexionar sobre el punto. Se ve a los comuneros como portadores de una identidad escindida, en el sentido de calificar su actitud como opuesta a lo que se consideraría una auténtica identidad de izquierda. El rechazo de los comuneros a la presencia de los pobladores se asociaría, para algunos ciudadanos, a una postura conservadora coherente con un proyecto de sociedad más cercano a un pensamiento de derecha. El conflicto analizado sería percibido por algunos ciudadanos como un resabio de experiencias de segregación global (como las erradicaciones masivas realizadas durante el gobierno militar) que aparecerían reñidas con un proyecto de justicia y de integración social, aspiraciones históricamente asociadas al discurso político de la izquierda, lo que resultaría contradictorio con la actitud de los comuneros.

Para un grupo muy minoritario de participantes de los foros, la actitud de los comuneros no favorecería la integración social en el sentido antes descrito, en tanto significa privar a otros ciudadanos de su derecho a la vivienda y a la 
ciudad. Es interesante subrayar el hecho de que casi la mayoría de las declaraciones que estarían por la instalación de los pobladores en los terrenos aledaños a la comunidad denuncian lo que perciben como una actitud clasista encubierta, contradictoria con un proyecto democrático que pretende igualar oportunidades, como sería el de los gobiernos de la Concertación, teóricamente heredero de la tradición instaurada por el gobierno de Salvador Allende. No obstante, otras opiniones consideran que la actitud del gobierno refuerza la sensación progresiva de pérdida de control de los ciudadanos sobre la ciudad y sus barrios.

En cuanto al valor del esfuerzo y la propiedad privada, un elemento fuertemente referido por los ciudadanos para legitimar la actitud de los comuneros se fundamenta en la importancia del esfuerzo y al ahorro individual - vinculados a una ética del trabajo y la corrección - como únicos garantes de la posibilidad de acceder a una vivienda. Esta idea estaría fuertemente arraigada entre los participantes de los foros, restringiendo el acceso al campo de las competencias económicas y socioculturales que posea un sujeto y su familia. El gobierno debe básicamente comprometer acciones que garanticen este derecho a quienes han demostrado que, en virtud de su conducta responsable, son merecedores de la protección del Estado, tanto de las personas como de sus bienes. Ello resulta complementario con la legitimidad conferida hoy día al sector privado como gestor y administrador de seguros y prestaciones sociales, abandonando la pretensión universal asociada a la propuesta del Estado de Bienestar.

Respecto a la distinción, las opiniones de los participantes de los foros permiten inferir dos cuestiones significativas. La primera, que los habitantes de la toma serían portadores de una identidad social negativa, en tanto son percibidos como un grupo de referencia negativo. Si a ello se suman otras atribuciones que van en esta misma línea, no se está frente a una cuestión que implique solo la dimensión identitaria, sino la totalidad de la existencia. No desear compartir el espacio urbano con quienes han sido definidos en los términos expuestos en las opiniones analizadas (delincuentes, drogadictos, aprovechadores, flojos) no resulta extraño, sino, al contrario, sería un gesto natural, casi necesario, para protegerse de la amenaza que su proximidad supone.

\section{Como subraya un participante:}

"En este caso, desde un punto de vista sociológico, la lógica nos dice que es más saludable respetar la estratificación que se genera espontánea y naturalmente y no forzar una integración social que más bien puede producir resentimientos y conflictos ahora y en el futuro. No se trata de discriminar, sino de respetar la normal y natural evolución de los diferentes grupos sociales. La integración se produce cuando un individuo o un grupo de individuos supera con esfuerzo y trabajo los límites de su medio y accede a un grupo de condiciones superiores al suyo y no por un decreto legal.”

La segunda, se vincula con la importancia del papel atribuido al Estado en la defensa de los derechos de propiedad adquiridos por cierto sector. Derechos que se hacen extensivos no solo a la plusvalía de las viviendas, sino también de las comunas, plusvalía que se vería amenazada con la presencia de vecinos a quienes se les atribuyen prácticas culturales contrarias al prototipo del buen ciudadano. El Estado estaría llamado a garantizar, en consecuencia, la homogeneidad del perfil sociocultural de los habitantes de la ciudad, absteniéndose de emprender iniciativas que generen una mezcla social que se percibe con desconfianza y temor. Así, para la mayoría de los participantes de los foros, el Estado no debe jugar ningún rol frente al tema de la segregación urbana; su tarea sería garantizar que las reglas del juego (leyes y valores culturales) asociadas a la legitima obtención y goce de un bien, en este caso la vivienda, se respeten. Hay implícita en estos discursos la exaltación de un estilo de vida asociado al esfuerzo, la corrección, la respetabilidad, la honestidad, la observancia de las leyes, y que se opondría al modo de vivir de los habitantes de la toma. De este modo, la solución del gobierno de ceder terrenos a los pobladores para que se instalen en el sector es percibida como la premiación inmerecida de un comportamiento oprobioso (aprovechador, transgresor, delincuente), propio de personas que no han hecho ningún esfuerzo por lograr lo mismo que otros han debido obtener con ahorro y trabajo, sintiéndose, de algún 
modo agredidos por la actitud de un Estado que estaría premiando la irresponsabilidad.

En cuanto a la dimensión social del papel del Estado, este debe generar alternativas de vivienda social, es decir, favorecer el acceso al bien, garantizando solo un piso básico, dándole un carácter más asistencial o compensatorio al problema que presentan los pobladores de la toma. Sin embargo, no se observa el mismo acento en las declaraciones de los comuneros respecto al tipo de rol que debe jugar el Estado. La mayoría de ellos subraya su importancia como garante del respeto por la legalidad y la normativa vigentes, fundamentalmente en aquello que toca el plano regulador de la comuna. Esta regulación tendría como referente y horizonte la sustentabilidad del territorio en su conjunto, y también, la apelación del derecho a preservar un estilo de vida en una perspectiva de largo plazo. Así, los habitantes de la comunidad ecológica denuncian aquellas actitudes en las que habría incurrido la autoridad pública, que consideran transgresiones a los acuerdos o normas previamente pactados, sean estos de carácter formal - expresados en la ley - o bien de carácter menos formal, manifestados en acuerdos de palabra suscritos entre comuneros y personeros públicos y que estos últimos habrían pasado a llevar.

Finalmente, en cuanto a la categoría seguridad, esta solo aparece referida por los participantes en los foros y no por los habitantes de la comunidad ecológica para avalar la legitimidad del rechazo a los pobladores. La valoración que hacen los propios comuneros sobre la comunidad en tanto condominio privado no se relaciona con la seguridad ciudadana en sus dimensiones subjetiva u objetiva, sino más bien con cuestiones de identidad y motivación - como ya fue subrayado -, que no necesariamente se asocian, al menos en la dimensión manifiesta del discurso, a la necesidad de distinguirse respecto del afuera, sino de afirmar una opción por ser y hacer ciudad a la que se adhiere fuertemente y que, por lo tanto, se está dispuesto a defender.

La cuestión de la seguridad, no obstante, sí sería un componente central de la legitimidad conferida por los ciudadanos de los foros a la actitud de los comuneros. Para ellos, el rechazo de estos a aceptar a los pobladores de vecinos se relacionaría fuertemente con la necesidad de protegerse de la amenaza de la delincuencia que su presencia conlleva. Observamos aquí una fuerte vinculación entre los temas de seguridad y la cuestión de la distinción en el sentido de Bourdieu (1977). Ello, en tanto la delincuencia no sería un rasgo más, sino un elemento constitutivo de la identidad de los pobladores.

\section{Conclusiones}

Este estudio refrenda el supuesto de que los espacios residenciales cerrados serían el resultado de procesos socioespaciales específicos asociados a cuestiones de identidad y distinción (Arriagada y Rodriguez, 2003), lo que se confirmaría tanto a partir de la reacción de rechazo de los comuneros ante la posibilidad de tener de vecinos a los pobladores, como en la legitimidad conferida a dicho rechazo por los ciudadanos que opinaron en los foros. Ello torna difícil la posibilidad de que los pobres se identifiquen con la ciudad y sus habitantes como conjunto, desarrollando pertenencia, cohesión e identidad respecto de la misma.

Cabe destacar el carácter asimétrico que tuvo el manejo y la gestión del conflicto por parte de las autoridades públicas. Una salida más democrática se podría haber buscado en lo que Borja (2003) llama la innovación política local, que referiría al establecimiento de políticas de proximidad que consideren el contexto inmediato, las situaciones individuales, se apoyen en la cooperación social, en la prevención e inserción y que posean un carácter multidimensional e integral. Lo anterior, en oposición a la búsqueda de soluciones en las políticas sociales nacionales y centralizadas y, por lo tanto, en las formas clásicas de gestión de dichas políticas. Se trata de acciones locales, continúa Borja (2003), que establezcan una separación e, incluso, una confrontación con el sistema político nacional, lo que supondría promover la autogestión y la autodeterminación local, incentivar la democracia deliberativa (y no solo la representativa) y el fortalecimiento de los sistemas políticos/legales como instrumentos eficaces para el ejercicio y protección de derechos ciudadanos Este criterio se puede aplicar al conflicto analizado, cuya emergencia y modalidad de enfrentamiento se vincularía con 
la cuestión de la gobernabilidad, es decir, con el lugar de la sociedad civil y de la ciudadanía en el desarrollo de un proyecto democrático para la construcción de ciudad (Álvarez, Contreras y Sánchez, 2006).

En este marco, sostienen Borja y Castells (2004), "los gobiernos locales adquieren un papel político revitalizado en consonancia con la crisis estructural de competencias y poder con que se encuentran los Estados nacionales en el nuevo sistema global" (pp. 17-18). Un conflicto como el descrito podría haberse resuelto mejor de haber sido abordado desde la dimensión local, dada la menor dificultad que tienen los gobiernos locales para trabajar la cuestión de la integración de las diferencias sociales y culturales, que a menudo se pierde en la acción de los Estados nacionales, por cuanto deben velar por el "equilibrio entre grupos sociales muy diversos y por tener que acentuar los aspectos instrumentales de la política sobre la dimensión integradora de las instituciones (...)" (Borja y Castells, 2004, p. 17).

Las opiniones de los comuneros confirman que Santiago sería una ciudad donde predomina un urbanismo de productos (Borja, 2003), con baja regulación estatal y una inexistente democracia deliberativa. A la liberalización del precio del suelo urbano de fines de la década del '70 se adiciona la falta de políticas de planificación que tengan como centro la relación entre espacio urbano, integración social y calidad de vida urbana. El alegato de los comuneros representaría el punto de vista ciudadano, siendo ésta una categoría clave levantada como mediación que define a los sujetos frente al Estado y, al mismo tiempo, los protege de su poder. Respecto del punto anterior, conviene subrayar que aun existiendo una auténtica voluntad política de contrarrestar el impacto de estos procesos, no es posible pasar por alto la complejidad del actual escenario.

Sobre ello, se sostiene que en Europa, aun habiendo políticas respecto de diferentes sectores, hasta la década del '90 no existían políticas específicas para las grandes ciudades orientadas a contrarrestar el impacto de los proceso de transformación en curso. En el informe sobre Gober- nabilidad de las Áreas Metropolitanas, se sostiene que "la organización de las áreas metropolitanas es una cuestión no resuelta en casi todo el mundo. Son raras las soluciones que se pueden considerar satisfactorias, es decir que corresponden a los objetivos planteados y aun, en estos casos, son polémicas" (Borja, 2002, p. 7).

Asumiendo el impacto profundo del modelo económico dominante sobre la conformación social y espacial de la ciudad, se trata también de "una cuestión heredada del pasado que corresponde a la etapa de la ciudad industrial y a la dialéctica centro-periferia que la caracterizaba. Hoy esta dialéctica también existe pero a una escala regional y es mucho más compleja (...)" (Borja, 2002, p. 7). A ello se agregan la insuficiencia de soluciones planificadoras, la falta de financiamiento de políticas públicas coherentes entre sí y que sirvan a un mismo propósito, junto con la crisis del tipo de planeamiento territorial tradicional y la incapacidad de las entidades específicas sectoriales, que si bien resuelven problemas puntuales, no solucionan la crisis en la que ha entrado la gestión y administración del territorio urbano, crisis que se acentúa con la debilidad de las políticas integradas y reequilibradoras, a favor de un funcionamiento preferentemente tecnocrático (Borja, 2002).

Respecto al papel que debe jugar el Estado en materia de vivienda e integración social, los ciudadanos de los foros parecen identificarse fuertemente con la propuesta neoliberal, que tiende a separar lo público de lo privado. Se postula como tarea de lo público cuidar los bienes y los barrios de quienes ya están ejerciendo su derecho a la vivienda, ejercicio que han ganado mediante el ahorro y el esfuerzo, y, también, cuidar de la población que no entra en la competencia del mercado, es decir, cuidar de los pobres mediante subsidios y asistencia. En síntesis, la propuesta de la universalidad restringida, basada en la valoración del individuo y de su acción racional, considerando que estos individuos están dispuestos a compartir el riesgo, asegurando los gastos en el futuro de acuerdo con su capacidad de pago (Álvarez et al., 2006). Así, las declaraciones de quienes opinaron en los foros, pueden ser leídas desde la Teoría de la Elección 
Racional ${ }^{8}$, que postula como supuestos: la dependencia de las prácticas sociales de la intención de los sujetos que las realizan, el carácter racional de la acción social, el hecho de que esta acción requiere de información lo más completa y verídica posible y la capacidad de los individuos de distinguir entre situaciones de riesgo e incertidumbre, asumiendo las consecuencias de sus actos. La vivienda propia y el derecho a su protección mediante la promesa de un Estado garante de su seguridad suponen la existencia de consumidores que actúan racionalmente, capaces, por sus conocimientos, de tomar decisiones adecuadas consideradas las mejores para sí mismos.

La identidad, su preservación y defensa serían el fundamento de la lucha de los habitantes de la comunidad para conservar su espacio y la forma de vida a él asociada, en tanto para los participantes de los foros sería la distinción. Ello podría ser explicado, en parte, por el hecho de que los comuneros se definen, en primera instancia, como detentores de un proyecto de vida en la ciudad y no como ciudadanos en búsqueda de seguridad o diferenciación respecto del afuera. Si bien la globalización tiende a la homogenización de patrones de desarrollo económico, pautas culturales y conductas, ello no pareciera significar que la cultura, la identidad, la historia local dejen de tener importancia para los habitantes de la ciudad, así como tampoco desaparecen las necesidades de mejoramiento de los espacios cotidianos y la calidad de vida y de convivencia social que ahí se despliega. Aunque el componente identitario es reconocido por los participantes de los foros como un factor importante, prevalecen el valor del esfuerzo, la propiedad privada y el rol que el Estado debiera jugar en su defensa y protección. Asimismo, la reacción de los ciudadanos, deja en evidencia que la segmentación socioeconómica del espacio constituiría un proceso contradictorio, pues a él se vinculan un conjunto de dinámicas socioculturales que ponen de manifiesto no solo la fuerte resistencia a la integración social entre clases, sino también el rechazo al contacto social.

\footnotetext{
8 También conocida como Teoría de la Competencia, tiene su sustento filosófico en el Liberalismo y en los principios que fundan esta concepción, a saber: mi vida, mi libertad, mis bienes.
}

Este rechazo estaría justificado por una serie de atribuciones que determinan una identidad negativa para los pobladores, presentándolos como potencial amenaza para la preservación de un estilo de vida armonioso con la naturaleza y respetuoso del medio ambiente, amenaza para la seguridad ciudadana y la conservación de la propiedad privada y amenaza hacia un modelo de vida fundado en el esfuerzo y el ahorro y contrario al aprovechamiento y la pereza.

De este modo, para los participantes de los foros, la segmentación social del espacio se sostiene, produce y reproduce sobre la base de una naturalización de las diferencias entre sectores sociales, haciendo una clara distinción entre ciudadanos que pertenecerían, en virtud de sus méritos económicos, a una cultura de la decencia, mientras los otros no serían todavía merecedores de dicho reconocimiento. Así, se refuerza la relación entre categorías de ciudadanos y calidad del espacio urbano, existiendo sectores que concentran mayores posibilidades de acumulación, acceso a redes y recursos y mayor plusvalía de sus viviendas y comunas solo por el territorio en el que habitan.

La seguridad no aparece mencionada por los comuneros como fundamento de su rechazo a los pobladores. Ello bien podría deberse a la significación que atribuyen a la comunidad ecológica como proyecto de vida y al perfil sociocultural de sus miembros. Estos rasgos no serían generalizables a los habitantes de los condominios cerrados que pueblan la ciudad de Santiago, para quienes esta opción no estaría vinculada necesariamente a un proyecto de vida, ni a altos niveles de cohesión social como los observados en la comunidad ecológica, sino más bien a la búsqueda de homogeneidad sociocultural hacia adentro y donde la seguridad se vuelve un argumento central.

Este estudio concluye que, mirada bajo el prisma de la fragmentación socioespacial y de la segregación urbana, la comunidad ecológica, aun constituyendo una experiencia innovadora, no sería generadora de sinergia colectiva en el sentido de instalar a nivel público la importancia de repensar las necesidades sociales de los actuales habitantes urbanos, ni tampoco los vínculos sociales y medioambientales que podrían estarse creando como alternativas a 
los vigentes. Tampoco pareciera generarse en la ciudadanía una reflexión más profunda y compleja, orientada a pensar la ciudad en su conjunto. Tanto los ciudadanos de los foros como los integrantes de la comunidad ecológica aparecen fuertemente identificados con la contingencia del conflicto y sus implicancias políticas de corto plazo, sin mayor reflexión sobre lo que este desacuerdo levanta como preguntas de fondo para la ciudad de Santiago, entre otras la disposición como ciudadanos al contacto social y al papel que le compete al Estado en la generación de condiciones para que este contacto se vea favorecido. Si bien los valores que sostienen una iniciativa como la comunidad ecológica de Peñalolén y su defensa por preservar un estilo de vida podrían ser ejemplos de modos alternativos de ser y hacer ciudad, no lograron generar a nivel público discursos en favor de una propuesta de ciudad integradora que pudiera contrarrestar los efectos negativos de las actuales dinámicas de ocupación del territorio urbano, poner en el centro del debate cuestiones relativas a la falta de regulación estatal en materia de suelo urbano, ni tampoco generar un diálogo social en torno a la debilidad de la respuesta ciudadana frente a ambos fenómenos.

\section{Referencias bibliográficas}

Álvarez, A., Contreras, A. \& Sánchez, D. (2006). Sociedad civil y ciudadanía: pistas para su comprensión y fortalecimiento: estudio de casos múltiples. Perspectivas: Notas sobre Intervención y Acción Social, 17, 7-30.

Aránguiz, J. (2004) Santiago de Chile, nueva arquitectura y espacio público. Arquitecturas de fin de crisis. 1999-2004 [versión electrónica], Revista de Urbanismo, 11.

Arriagada, C. \& Rodríguez, J. (2003, octubre). Segregación residencial en áreas metropolitanas de América Latina: magnitud, características, evolución e implicaciones de política, Serie Población y Desarrollo, 47. Recuperado el 6 de febrero de 2005, de http://www.cepal.org.

Bañados, F. (2003, diciembre) Comunidad Ecológica de Peñalolén. La visión de los colonos y sus miedos de cara al futuro: ¿paraíso perdido?, Diario electrónico El Mercurio, recuperado el 5 Abril 2005, de www.emol.com.

Barros, P., De los Ríos, D. \& Torche, F. (1996, junio): Lecturas sobre la
Exclusión Social. Documento de Trabajo OIT, 31. Recuperado el 31 de marzo de 2003, de http://www.ilo.org.

Borja, J. \& Castells, M. (2004) Local y global: la gestión de las ciudades en la era de la información (7a Ed.) Madrid: Taurus.

Borja, J. (2003) La Ciudad Conquistada (1 $1^{\mathrm{a}}$ ed.) Madrid: Alianza Editorial.

(2002, septiembre) Informe sobre la gobernabilidad de las áreas metropolitanas en el mundo. Centro de Documentación Virtual $M P G O B$ 001, Recuperado el 12 Diciembre de 2005, de http://www.regionbogotacundinamarca.org.

Bourdieu, P. \& Passeron, J.C. (1977) La reproducción: elementos para una teoría del sistema de enseñanza (1 ${ }^{\text {a }}$ Ed.) Barcelona: Laia.

Espinoza, V. (1988). Por una historia de los pobres de la ciudad (1 ${ }^{\text {a }}$ Ed.). Santiago: Ediciones SUR.

Giglia, A. (2003). Espacio público y espacios cerrados en la Ciudad de México. Universidad Autónoma Metropolitana, Iztapalapa, Ciudad de México, División de Ciencias Sociales y Humanidades, Departamento de Antropología. Recuperado el 8 de agosto de 2005, de http://uam-antropologia.info/web/articulos.

Hevia, S. (2003). La política social de vivienda en Chile: una Mirada Crítica. Perspectivas, 13, 57-75.

Hidalgo, R., Salazar, A. \& Álvarez, L. (2003). Los condominios y urbanizaciones cerradas como nuevo modelo de construcción del espacio residencial en Santiago de Chile (1992-2000) \{versión electrónica\}. Revista Electrónica de Geografia y Ciencias Sociales, Scripta Nova, 7, 146.

López, L., Rodríguez, I. (2004). Miedo y consumo: el encerramiento habitacional en México y Madrid. Perspectivas Urbanas, 5. Recuperado el 23 de noviembre de 2004 de www.etsav. upc.es

Miranda, M. (2003, 20 julio): "La toma” y la "comunidad ecológica": entre la ficción y Peñalolén. El periodista, la voz atrevida, 2, 40. Recuperado el 2 de febrero de 2004, de http://www.elperiodista.cl

Pol, E., Guardia, J., S. Valera, Wiensenfeld, E. \& Uzzell, D. (2000). Cohesión e identificación 
en la construcción de la identidad social: la relación entre ciudad, identidad y sostenibilidad. Dossier Revista Universidad de Guadalajara, 19. Recuperado el 20 de agosto de 2007 de http://www.cge.udg.mx/revistaudg.

Raposo, A., Raposo, G. \& Valencia, M. (2005). Remodelación urbana e ideología. Un ensayo de interpretación crítica de la obra arquitectónica y urbanística de CORMU en Santiago 1966-1976. En A. Raposo, G. Raposo \& M.
Valencia, La interpretación de la obra arquitectónica y proyecciones de la politica en el espacio habitacional (pp. 224-313).

Sabatini, F., Cáceres, G. \& Cerda, J. (2001). Segregación residencial en las principales ciudades chilenas: tendencias de las tres últimas décadas y posibles cursos de acción \{versión electrónica\} EURE, 27, 82, 21-42. 